\title{
Relationship of Sex, Age, and Preference Level of Sour Food with Sweetness Sensitivity in Young Japanese Adults
}

\author{
Ken-ichi Aoyama ${ }^{* 1,2}$, Yuichiro Okino ${ }^{3}$, Hiroshi Yamazaki ${ }^{1,2}$, Rena Kojima ${ }^{1,2}$, Masahiro Uchibori ${ }^{1}$, \\ Yasuhiro Nakanishi ${ }^{1}$, Yoshihide Ota $^{1}$ and Akihiro Kaneko ${ }^{1}$ \\ ${ }^{1}$ Department of Oral and Maxillofacial Surgery, Tokai University School of Medicine, 143 Shimokasuya, Isehara, Kanagawa 259- \\ 1193, Japan \\ ${ }^{2}$ Department of Oral and Maxillofacial Surgery, Tokai University Oiso Hospital, 21-1 Gakkyo, Oiso, Kanagawa 259-0114, Japan \\ ${ }^{3}$ Department of Health and Welfare, Okayama Prefectural Government, Uchi-Yamashita 2-4-6, Kita-ku, Okayama, 700-8570, Japan
}

Received: July 31, 2017; Accepted: November 03, 2017; Published: November 20, 2017

*Corresponding author: Ken-ichi Aoyama, Assistant Professor, Department of Oral and Maxillofacial Surgery, Tokai University School of Medicine, 143 Shimokasuya, Isehara, Kanagawa, 259-1193, Japan ,Tel: +81 463931121 ext.2430, Fax: +84 46396 2892, E-mail: k-aoyama@tokai-u.jp

\section{Abstract}

Objectives: The aim of this study was to establish a prediction system for taste sense according to questionnaire surveys about dietary background. This study is a follow-up to a previously published Previous Article.

Research Methods \& Procedures: A total of 63 healthy Japanese participants, aged 20-28 years, who did not have smoking and drinking alcohol habit, were surveyed. Questionnaires about background, which included Body Mass Index (BMI), preference level of using dipping sauces in eating, eating snack food, drinking soft drinks, and preference levels for four tastes were performed. Taste examination (sweetness, saltiness, sourness, and bitterness) was performed using the dropped disc method. Correlation and multiple regression analyses were performed between the taste sense properties and questionnaire survey data.

Results: Multiple regression analysis showed that sweetness sensitivity (in which a higher score indicates lower sensitivity) was significantly affected by dietary background properties, with the strongest influence of sex, age and preference level of sour food. The following prediction equation was determined: Sweetness sensitivity $=3.6+[-0.25 \times$ sex (male: 0 , female: 1$)]+(-0.03 \times$ age $)+$ [- $0.13 \times$ preference level of sour food (1: strongly disagree, 2 : disagree, 3: neither agree nor disagree, 4: agree, 5: strongly agree)]. Analysis of variance showed an overall significant effect of these variables on sweetness sensitivity $\left(\mathrm{R}^{2}=0.48, P<0.01\right)$.

Conclusion: Sweetness sensitivity could be predicted by sex, age, and preference level of sour food, through a multiple regression analysis, in a healthy Japanese population.

Keywords: Taste sensory prediction; Sweetness sense; Dietary backgrounds; Preference level of sour food; sex; age.

\section{Introduction}

The sensory preference for food and food palatability may contribute to over consumption and constitute a risk factor of weight gain [1]. In most developed countries, including Japan, over-eating is a risk factor for development of unhealthy diabetes, and premature mortality, as a consequence of obesity [2-4]. Taste sense plays an important role in dietary life $[5,6]$.Taste is affected by aging, diet and life style conditions and backgrounds, and strongly affected by aging [7].

Evaluation methods of taste sense are somewhat limited, as they rely on the subjective reaction of patients. An objective examination for evaluating the taste sensory system is required. We analyzed correlations between basic taste sense (sweetness, saltiness, sourness, and bitterness) and biochemical data for young, healthy participants, which indicated that saliva $\mathrm{pH}$ affects sweetness sensitivity.

Food preference relates to food habituation and habituation may be a basic mechanism underlying sensory specific satiety $[8,9]$. However, there is no evidence regarding a relationship between preference level of basic taste sensations and dietary preference.

In the present study, we evaluated the taste sense in healthy adult subjects to advance the research of our previous report, in order to develop a simple prediction system of taste sense. 63 of 100 Japanese participants who were reported on our previous report participated in this study [10].They did not have any disease, including oral disorders. All participants completed questionnaire surveys about backgrounds and dietary preference, as well as a taste examination, which utilized identical methods to the previous report [10]. Taste analysis was based on a common, 
clinically applied kit that is used for detecting the four basic taste sensations (sweet, bitter, sour, salty), in five step concentrations.

\section{Materials and Methods}

\section{Participants, Ethics and Taste Examination}

This study included 63 Japanese participants ( 40 males and 23 females), aged 20-28 years (mean: 24.2 years) without physical, oral, or mental disability, as well as no medication, smoking and/ or, alcohol drinking habit including occasional drinkers. The participants were asked to not brush their teeth within $45 \mathrm{~min}$ prior to sample collection and to not eat within 2 hours of taste examination. Taste examinations were performed under resting conditions in a quiet room in the morning, between 9:00 a.m. and 12:00 noon. We used Taste Disc (Sanwakagaku, Aichi,Japan), which includes filter paper disks $8 \mathrm{~mm}$ in diameter and taste solutions, which were sequentially diluted (in 5 stages from $80 \%$ sucrose, $20 \% \mathrm{NaCl}, 8 \%$ tartaric acid, and $4 \%$ quinine hydrochloride). The sensitivity at which each taste was recognized in the center of the tongue tip was determined by testing increasing concentrations of each solution. A smaller absorbance value was interpreted as a more sensitive taste sense, in which a score of 1 is considered the most sensitive and a score of 5 is considered no sensitivity, which was same as our previous report [10]. We examined in the order of sweetness, salty, sourness and bitterness sensitivity for each participants.

This study was approved by the ethics committee of the Tokai University School of Medicine (13R034).

\section{Questionnaire Surveys}

Questionnaire surveys about background, which included body mass index (BMI), preference level of using dipping sauces while eating (e.g., soy sauce, catsup, vinegar, salad dressing, etc.) snack food/soft drink consumption, and preference level for four tastes (i.e., sweetness, saltiness, sourness, and bitterness) were performed in participants. Preference levels for each status were measured on a five-point Likert scale [11].

\section{Statistical Analyses}

All statistical analyses [i.e., the estimation of sample size, univariate analysis (correlation analysis and correlation coefficients), and multivariate analysis (multiple logistic regression)] were evaluated with the same method as our previous report [10].

All statistical analyses were performed using the SPSS (version 23 ), and $\mathrm{P}<0.05$ was considered statistically significant. Sex and BMI were coded by dummy variables (male: 0 , female: 1) and (BMI $<18.5=1,18.5 \leq \mathrm{BMI}<25=2,25 \leq \mathrm{BMI}<30=3$, $30 \leq \mathrm{BMI}<35=4,35 \leq \mathrm{BMI}=5$ ). Preference level of each status were coded as strongly disagree $=1$, disagree $=2$, neither agree/ disagree $=4$, strongly agree $=5$.

\section{Results}

\section{Taste Examination}

The sensitivity results for each taste type of the 63 healthy subjects are shown in table 1 . The mean sensitivity values for sweetness, salty, sourness, and bitterness taste components were $97 \%, 98 \%, 98 \%$, and $97 \%$, respectively, for up to three absorbance measures.

\begin{tabular}{|c|c|c|c|c|}
\hline \multicolumn{6}{|c|}{ Table1: Taste Sensitivity Examination Profile } \\
\hline Taste & Sweetness & Salty & Sourness & Bitterness \\
\hline Absorbance & $\mathbf{n}(\%)$ & $\mathbf{n}(\%)$ & $\mathbf{n}(\%)$ & $\mathbf{n}(\%)$ \\
\hline 1 & $1(1.6)$ & $33(52.4)$ & $3(4.8)$ & $11(17.5)$ \\
\hline 2 & $43(68.3)$ & $23(36.5)$ & $36(57.1)$ & $43(68.3)$ \\
\hline 3 & $17(27.0)$ & $6(9.5)$ & $23(36.5)$ & $7(11.1)$ \\
\hline 4 & $0(0)$ & $1(1.6)$ & $1(1.6)$ & $2(3.2)$ \\
\hline 5 & $2(3.2)$ & $0(0)$ & $0(0)$ & $0(0)$ \\
\hline $\begin{array}{c}\text { Mean } \\
\text { absorbance }\end{array}$ & 2.4 & 1.6 & 2.4 & 2.0 \\
\hline
\end{tabular}

Number of participants for each taste absorbance test. Smaller absorbance values indicate greater taste sensitivity as previous report.

\section{Questionnaire Survey Data}

BMI distribution of participants was $<18.5=7,18.5 \leq \mathrm{BMI}$ $<25=45,25 \leq \mathrm{BMI}<30=8$, and $30 \leq \mathrm{BMI}<35=3$ participants. No participants exhibited a BMI greater than or equal to 35 . Other questionnaire survey data are shown in table 2,3 .

\begin{tabular}{|c|c|c|c|c|}
\hline \multicolumn{5}{|c|}{ Table 2: Questionnaire Results about Dietary Life } \\
\hline & $\begin{array}{c}\text { Dipping } \\
\text { sauces }\end{array}$ & $\begin{array}{c}\text { Eating } \\
\text { snack } \\
\text { foods }\end{array}$ & $\begin{array}{c}\text { Drinking } \\
\text { soft } \\
\text { drinks }\end{array}$ & $\begin{array}{c}\text { Drinking } \\
\text { coffee or tea }\end{array}$ \\
\hline $\begin{array}{c}\text { Preference } \\
\text { level }\end{array}$ & n (\%) & n (\%) & n (\%) & n (\%) \\
\hline 1 & $8(12.7)$ & $5(7.9)$ & $6(9.5)$ & $38(60.3)$ \\
\hline 2 & $10(15.9)$ & $3(4.8)$ & $18(28.6)$ & $8(12.7)$ \\
\hline 3 & $24(38.1)$ & $24(38.1)$ & $20(31.7)$ & $9(14.3)$ \\
\hline 4 & $15(23.8)$ & $25(39.7)$ & $15(23.8)$ & $4(6.3)$ \\
\hline 5 & $6(9.5)$ & $6(9.5)$ & $4(6.3)$ & $4(6.3)$ \\
\hline
\end{tabular}


Table 3: Questionnaire Results about Preference of Each Taste

\begin{tabular}{|c|c|c|c|c|}
\hline Taste & Sweet & Salty & Sour & Bitter \\
\hline $\begin{array}{c}\text { Preference } \\
\text { level }\end{array}$ & $\mathbf{n}(\mathbf{\%})$ & $\mathbf{n}(\%)$ & $\mathbf{n}(\%)$ & $\mathbf{n}(\%)$ \\
\hline 1 & $0(0)$ & $0(0)$ & $0(0)$ & $7(11.1)$ \\
\hline 2 & $1(0.2)$ & $0(0)$ & $4(6.3)$ & $22(34.9)$ \\
\hline 3 & $18(28.6)$ & $37(58.7)$ & $40(63.5)$ & $27(42.9)$ \\
\hline 4 & $32(50.8)$ & $20(31.7)$ & $16(25.4)$ & $4(6.3)$ \\
\hline 5 & $12(19.0)$ & $6(9.5)$ & $3(4.8)$ & $3(4.8)$ \\
\hline
\end{tabular}

Correlation between Taste Sensitivity and Questionnaire Survey Data

The results of univariate analyses for determining the correlation between each taste sensitivity value and questionnaire survey data are shown in table 4. Additionally, correlations among questionnaire survey measures are presented in table 5 .

Multiple regression analysis was performed using up to 3 variables. We extracted the independent variables that were most relevant to taste sense, as determined by the univariate analyses.

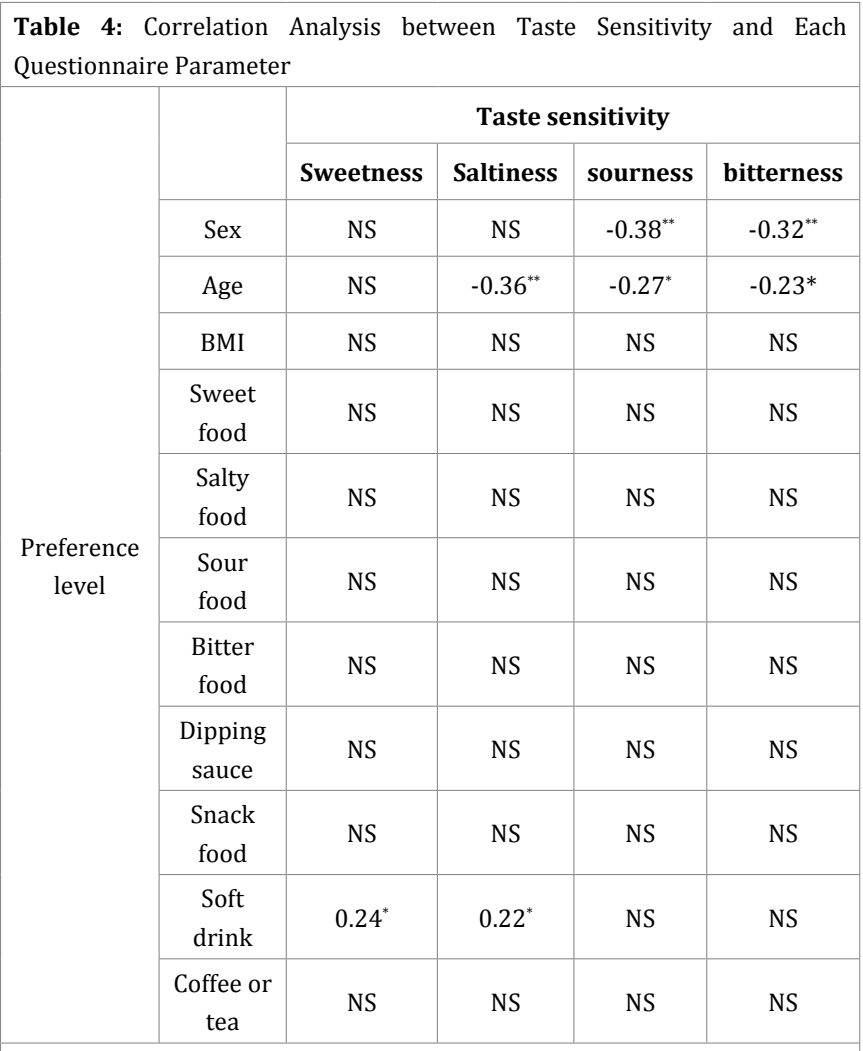

Correlation coefficients were evaluated according to the $R$ value. $R=0$, no linear relationship; $0.2<|\mathrm{R}| \leq 0.4$, weak linear relationship; $0.4<|\mathrm{R}| \leq 0.7$, moderate linear relationship; $0.7<|R|<1.0$, strong linear relationship; $|\mathrm{R}|=1$, perfect linear relationship. ${ }^{*} P<0.05$, $^{* *} P<0.01$, NS: not significant
Sweetness sensitivity was significantly influenced by background and questionnaire survey data in the multiple regression analysis $\left(\mathrm{R}^{2}=0.48, P<0.01\right.$, based on ANOVA), as shown in table 6 , and the following equation was obtained: Sweetness sensitivity $=3.6+[-0.25 \times$ sex (male: 0 , female: 1$)]+$ $(-0.03 \times$ age $)+[-0.13 \times$ preference level of sour food (1: strongly disagree, 2: disagree, 3: neither agree nor disagree, 4: agree, 5: strongly agree)]. Therefore, sex and preference level of sour food showed the strongest influence on sweetness sensitivity. BMI, preference level of salty and bitter food, dipping sauce use, snack food, soft drink, and coffee/tea consumption were dropped as non-significant during stepwise selection.

We confirmed that all parameters were in the range of $\pm 3 \mathrm{SD}$. Saltiness, sourness, and bitterness taste sensitivities were not significantly related to any factors tested.

\begin{tabular}{|c|c|c|c|c|c|}
\hline Table 5: Correlation Analysis of each Questionnaire Parameter \\
\hline \multirow{4}{*}{} & \multicolumn{4}{|c|}{ Preference level } \\
\cline { 2 - 6 } & Sweet & Salty & Sour & Bitter \\
\cline { 2 - 6 } & 2 & NS & NS & $-0.38^{* *}$ & $-0.32^{* *}$ \\
\cline { 2 - 6 } level & 3 & NS & $-0.36^{* *}$ & $-0.27^{*}$ & $-0.23^{*}$ \\
\cline { 2 - 6 } & 4 & NS & NS & NS & NS \\
\cline { 2 - 6 } & 5 & NS & NS & NS & NS \\
\cline { 2 - 6 } & sour food & NS & NS & NS & NS \\
\cline { 2 - 6 } & bitter food & NS & NS & NS & NS \\
\cline { 2 - 6 } & sauce & NS & NS & NS & NS \\
\cline { 2 - 6 } & snack food & NS & NS & NS & NS \\
\cline { 2 - 6 } & soft drink & $0.24^{*}$ & $0.22^{*}$ & NS & NS \\
\cline { 2 - 6 } & coffee or tea & NS & NS & NS & NS \\
\hline
\end{tabular}

Correlation coefficients were evaluated according to the $\mathrm{R}$ value. $\mathrm{R}=$ 0 , no linear relationship; $0.2<|R| \leq 0.4$, weak linear relationship; 0.4 $<|\mathrm{R}| \leq 0.7$, moderate linear relationship; $0.7<|\mathrm{R}|<1.0$, strong linear relationship; $|\mathrm{R}|=1$, perfect linear relationship. ${ }^{*} P<0.05,{ }^{* *} P<0.01$, NS: not significant

\section{Discussion}

Taste sense is related to chronic disease, medication use, smoking, alcohol consumption, and oral disorders, including dehydration of oral mucosa $[12,13]$. A recent study has shown that the preference and habituation for a specific beverage and food is associated with diet [14]. Therefore, we performed taste examination and conducted questionnaire surveys about dietary habituation and palatability, in healthy participants, who did not smoke or drink alcohol.

Of the four basic tastes, sweetness sensitivity plays the most important role in body weight control. This is because sugars that contribute to this sense are typically found in high-calorie food. Thus, sweetness sense is strongly linked to obesity [5, 6,15].Our 
Table 6: Multiple Regression Analysis of Taste Sensitivity with Questionnaire Parameters

\begin{tabular}{|c|c|c|c|c|c|}
\hline \multirow{2}{*}{ Sweetness threshold } & \multirow{2}{*}{$\begin{array}{l}\text { Partial regression } \\
\text { coefficient }\end{array}$} & \multirow{2}{*}{$\begin{array}{c}\text { Standard partial } \\
\text { regression } \\
\text { coefficient }\end{array}$} & \multirow{2}{*}{ p value } & \multicolumn{2}{|c|}{$95 \%$ CI } \\
\hline & & & & Lower limit & Upper limit \\
\hline Coefficient & 3.6 & & $<0.01$ & 2.97 & 4.2 \\
\hline Sex & -0.03 & -0.25 & 0.02 & -0.61 & -0.06 \\
\hline Age & -0.02 & -0.33 & $<0.01$ & -0.03 & -0.01 \\
\hline \multirow[t]{2}{*}{ Preference level of sour food } & -0.11 & -0.13 & $<0.01$ & -0.28 & -0.06 \\
\hline & & $\mathrm{R}^{2}=0.48$ & \multicolumn{3}{|c|}{ ANOVA $\mathrm{p}<0.01$} \\
\hline
\end{tabular}

Sweetness sensitivity was significantly influenced. The following equation was obtained: Sweetness sensitivity=3.6 + [-0.25 $\times$ sex (male: 0 , female: $1)]+(-0.03 \times$ age $)+[-0.13 \times$ preference level of sour food (1: strongly disagree, 2: disagree, 3: neither agree nor disagree, 4: agree, 5: strongly agree)]. Saltiness, sourness, and bitterness taste sensitivities were not significantly related to any of the questionnaire survey parameters

previous report suggested that sweetness sensitivity was the only sense of the four basic taste senses to be affected by saliva $\mathrm{pH}$, in a multiple logistic regression [10]. The current study also indicated, through multivariate analysis, that sweetness sensitivity was associated with dietary preference, which supports previous report [10].

Human thresholds for stimulus detection appear to differ between sexes for a broad range of stimuli, with women detecting basic taste stimuli at lower concentrations than men [16]. Female rats show a decreased number of aversive responses, but a greater number of ingestive behaviors, toward sweet tastes [17]. Additionally, female rats receive different sensory information from the periphery regarding salty and sour stimuli, whereas input concerning sweet and bitter tastes is not affected by sex [16]. A recent human study has shown that there are sex differences in taste sensitivity for the four basic tastes, and that sweetness sensitivity is more robust than the other tastes [18]. The present study supports the above findings, and is the first to report that sex (female) affects sweetness sense in a human study.

A recent report also suggested that young adults showed significantly lower recognition thresholds of basic four tastes than an early-elderly group (aged 69-71 years), and the earlyelderly group showed significantly lower recognition thresholds of those than a late-elderly group (aged 79-81 years) [18]. However, in the present report, age was negatively correlated with sweetness sense. Participants of present study were aged 20-28 years (mean: 24.2 years), which was younger than those of the afore mentioned report [18]. In addition, the current study examined participants who were healthy, not smoking, and did not consume alcohol. However, the previous study included participants who exhibited systemic/oral disease, drinking, and smoking habituation [10].

It is well known that sourness strongly relates to $\mathrm{pH}$ [19]. Our previous report indicated that saliva $\mathrm{pH}$ affects sweetness sense [10]. Habituation to the sweetness palatability is related with dietary symptoms such as obesity or lifestyle disease
[20]. Habituation to the sweetness palatability is related with dietary symptoms, such as obesity and/or lifestyle disease [20]. The present results support these findings, as multiple logistic regressions indicated a preference for sour food.

In conclusion, sweetness sensitivity was able to be predicted by sex, age, and preference level of sour food, via a multiple regression analysis, in a healthy Japanese population. However, the result of multiple regressions was significantly, but moderately influenced $\left(\mathrm{R}^{2}=0.48, P<0.01\right)$. Further studies are warranted to clarify the biological mechanism of sweetness sensory mechanism.

\section{Acknowledgement}

We are grateful to Professor Minoru Kimura, Dr. Yasushi Taniguchi, and Dr. Kagemasa Kajiwara, Department of Molecular Biology, Tokai University School of Medicine, for collecting the participants.

\section{Funding}

This work was financially supported by the Institute for Food and Health Science, Yazuya, Japan.

\section{Author contributions}

Conception and design of the study: K.A, Y-I.O, Y-H.O, A.K.

Collection, generation, assembly, analysis, and interpretation of data: K.A, H.Y, R.K

Drafting/revision of the manuscript: K.A, M.U, Y.N.

Approval of the final version of the manuscript: K.A, Y-I.O, Y-H.O.

\section{References}

1. Yeomans MR, Mobini S, Bertenshaw EJ, Gould NJ. Acquired liking for sweet-paired odours is related to the disinhibition but not restraint factor from the Three Factor Eating Questionnaire. Physiol Behav. 2009;96(2):244-252. doi: 10.1016/j.physbeh.2008.10.001 
2. Morita N, Nakajima T, Okita K, Ishihara T, Sagawa M, Yamatsu K. Relationships among fitness, obesity, screen time and academic achievement in Japanese adolescents. Physiol Behav. 2016;163:161166. doi: $10.1016 /$ j.physbeh.2016.04.055

3. Yoshiike N, Kaneda F, Takimoto H. Epidemiology of obesity and public health strategies for its control in Japan. Asia Pacific Journal of Clinical Nutrition. 2002;11:S727-S731. doi: 10.1046/j.1440-6047.11.s8.18.x

4. Medanic D, Pucarin-Cvetkovic J. [Obesity--a public health problem and challenge]. Acta med Croatica. 2012;66(5):347-355.

5. Connors P, Bednar C, Klammer S. Cafeteria factors that influence milkdrinking behaviors of elementary school children: grounded theory approach. J Nutr Educ. 2001;33(1):31-36.

6. Glanz K, Patterson RE, Kristal AR, Feng Z, Linnan L, Heimendinger J, et al. Impact of work site health promotion on stages of dietary change: the Working Well Trial. Health Educ Behav. 1998;25(4):448-463. doi: $10.1177 / 109019819802500404$

7. Syed Q, Hendler KT, Koncilja K. The Impact of Aging and Medical Status on Dysgeusia. Am J Med. 2016;129(7):753.e1-6. doi: 10.1016/j. amjmed.2016.02.003

8. Tepper BJ. 6-n-Propylthiouracil: a genetic marker for taste, with implications for food preference and dietary habits. Am J Hum Genet. 1998;63(5):1271-1276. doi: 10.1086/302124

9. Hetherington MM. Sensory-specific satiety and its importance in meal termination. Neurosci Biobehav Rev. 1996;20(1):113-117.

10. Aoyama KI, Okino Y, Yamazaki H, Kojima R, Uchibori M, Nakanishi Y et al. Saliva pH affects the sweetness sense. Nutrition. 2017;35:51-55. doi: 10.1016/j.nut.2016.10.018
11. Drinkwater BL. A comparison of the direction-of-perception technique with the Likert method in the measurement of attitudes. J Soc Psychol. 1965;67(2):189-196. doi: 10.1080/00224545.1965.9922270

12. Silvestre FJ, Silvestre-Rangil J, Lopez-Jornet P. Burning mouth syndrome: a review and update. Rev Neurol. 2015;60(10):457-463.

13. Ogawa T, Annear MJ, Ikebe K, Maeda Y. Taste-related sensations in old age. J Oral Rehabil. 2017;44(8):626-635. doi: 10.1111/joor.12502

14. Sluik D, Bezemer R, Sierksma A, Feskens E. Alcoholic Beverage Preference and Dietary Habits: A Systematic Literature Review. Crit Rev Food Sci Nutr. 2016;56(14):2370-2382. doi: 10.1080/10408398.2013.841118

15. Drewnowski A, Mennella JA, Johnson SL, Bellisle F. Sweetness and food preference. J Nutr. 2012;142(6):1142S-1148S. doi: 10.3945/ jn.111.149575

16. Martin LJ, Sollars SI. Contributory role of sex differences in the variations of gustatory function. J Neurosci Res. 2017;95(1-2):594603. doi: 10.1002/jnr.23819

17. Clarke SN, Ossenkopp KP. Taste reactivity responses in rats: influence of sex and the estrous cycle. Am J Physiol. 1998;274(3 Pt 2):R718-R1724.

18. Yoshinaka M, Ikebe K, Uota M, Ogawa T, Okada T, Inomata C, et al. Age and sex differences in the taste sensitivity of young adult, young-old and old-old Japanese. Geriatr Gerontol Int. 2016;16(12):1281-1288. doi: $10.1111 /$ ggi.12638

19. Kikut-Ligaj D, Trzcielinska-Lorych J. How taste works: cells, receptors and gustatory perception. Cell Mol Biol Lett. 2015;20(5):699-716. doi: 10.1515/cmble-2015-0042

20. Pepino MY, Mennella JA. Habituation to the pleasure elicited by sweetness in lean and obese women. Appetite. 2012;58(3):800-805. doi: 10.1016/j.appet.2012.01.026 